\title{
Desdobramentos da Atividade Orientadora de Ensino para a organização do ensino e para a investigação sobre a atividade pedagógica
}

DOI 10.26512/lc.v24i0.21851

\author{
Wellington Lima Cedro \\ Universidade Federal de Goiás - UFG \\ Vanessa Dias Moretti \\ Universidade Federal de São Paulo - UNIFESP \\ Sílvia Pereira Gonzaga de Moraes \\ Universidade Estadual de Maringá - UEM
}

\section{Resumo}

Este texto tem como objetivo discutir os desdobramentos do conceito de Atividade Orientadora de ensino (AOE) para a organização do ensino e para o desenvolvimento de pesquisas educacionais. Para tanto, foi realizada uma investigação de caráter documental em que se analisa dezenove teses de doutorado produzidas no âmbito do Grupo de Estudos e Pesquisa sobre Atividade Pedagógica (GEPAPe), no período de 2003 a 2016. Assim, a análise mostra como a $\mathrm{AOE}$ estava inicialmente, ligada à organização do ensino, e que, posteriormente, ela passa a ser compreendida, também, como instrumento teórico-metodológico para o desenvolvimento das pesquisas em educação, a qual tem como objeto a atividade pedagógica.

Palavras-chave: Atividade orientadora de ensino. Organização do ensino. Pesquisa educacional. 


\section{Resumen}

Este trabajo tiene como objetivo discutir los desdoblamientos que el concepto de Actividad Orientadora de la enseñanza (AOE) tiene tanto para la organización de la enseñanza y para el desarrollo de investigaciones educativas. Este trabajo bibliográfico analiza 19 tesis de doctorado producidas en el ámbito del Grupo de Estudios e Investigación sobre Actividad Pedagógica (GEPAPe), en el período de 2003 a 2016. El análisis muestra cómo la AOE estaba inicialmente, ligada a la organización de la enseñanza, y que, posteriormente se pasa a ser comprendida también, como instrumento teórico-metodológico para el desarrollo de las investigaciones en educación, la cual tiene como objeto la actividad pedagógica.

Palabras-clave: Actividad Orientadora de la enseñanza. Organización de la enseñanza. Pesquisa educacional.

\section{Abstract}

The objective of this work is to discuss the consequences that the concept of Teaching-orienteering Activity (TOE) has for both the teaching organization and the development of educational research. This bibliographic work analyzes 19 doctoral theses produced within the scope of the Group of Studies and Research on Pedagogical Activity (GEPAPe), from 2003 to 2016. The analysis shows how the TOE was initially linked to the teaching organization and that, later, it is also understood as a theoretical-methodological instrument for the development of research in education, which has as its object the pedagogical activity.

Keywords: Teaching-orienteering Activity. Teaching organization. Educational research. 


\section{Resumé}

Ce texte a pour objectif de discuter des développements du concept d'activité d'orientation l'enseignement (AOE) pour l'organisation de l'enseignement et pour le développement de la recherche en éducation. Une recherche documentaire a été réalisée pour analyser dix-neuf thèses produites dans le cadre du Groupe d'études et de recherches sur l'activité pédagogique (GEPAPe), de 2003 à 2016. L'analyse montre comment l'AOE était initialement lié à l'organisation de l'enseignement et que, par la suite, il est également compris comme un instrument théorique et méthodologique pour le développement de la recherche en éducation, qui a pour objet l'activité pédagogique.

Mots-cles: Activité d'orientation l'enseignement. organisation de l'enseignement. Recherche pédagogique.

\section{Introdução}

O objetivo do presente texto é refletir sobre os desdobramentos do conceito de Atividade Orientadora de Ensino (AOE) como instrumento teórico-metodológico para a organização do ensino e para a pesquisa em educação, a qual tem como objeto central a atividade pedagógica. A atividade pedagógica é compreendida como o "trabalho educativo sistemático e intencional com as objetivações humanas genéricas nas diferentes esferas da vida, contribuindo para que estas sejam apropriadas pelas novas gerações, apresenta-se como determinante para a formação da personalidade" (Araújo; Moraes, 2017, p. 52). Decorre, portanto, que ela é entendida como uma especial atividade humana e que, atualmente, a escola constitui-se como o espaço institucionalizado para seu desenvolvimento, em razão do seu caráter sistematizado.

O conceito de AOE foi produzido, primeiramente, por Moura (1992) com o objetivo inicial de buscar "princípios para organização do ensino". Nas suas palavras:

A atividade orientadora é uma ação organizada a ser desenvolvida em sala de aula. Ela é quem define os momentos principais do ensino: o problema desencadeador da aprendizagem; a organização do espaço onde se realizará; as sínteses necessárias para a compreensão do conceito em pauta e a avaliação do acompanhamento do trabalho pelos alunos. (Moura; 1992, p. 64)

Assim, a origem do conceito AOE reside na organização do ensino. Mas, que ensino? $O$ ensino que dê condições para os sujeitos apropriarem-se dos conhecimentos científicos 
e desenvolverem suas capacidades intelectivas. Neste momento de produção do conceito, a atividade orientadora se materializava em ações e instrumentos que o professor poderia utilizar para o desenvolvimento do ensino de determinado conteúdo escolar. Inclusive, no processo inicial de consolidação da atividade orientadora ela foi compreendida, por alguns, como o "problema desencadeador da aprendizagem". Contudo, é importante considerar que em seu germe já trazia uma estrutura que ia além desses elementos, revelava a direção mais generalizada para organização do ensino, visto que contemplava a tríade essencial da atividade pedagógica: conteúdo a ser ensinado, a forma mais adequada e os sujeitos-aprendizes.

Há que se destacar, também, que na sua nascente, mesmo tendo como foco o ensino, o conceito de $A O E$ não esteve separado da investigação sobre a atividade pedagógica, visto que dela emerge uma forma de pesquisa em educação na qual a captação dos dados se insere na intervenção do pesquisador no processo de organização, execução e análise dos dados sobre a atividade pedagógica, objeto da educação escolar.

Com a consolidação do Grupo de Estudos e Pesquisas sobre a Atividade Pedagógica $(\mathrm{GEPAPe})^{1}$; o aprofundamento dos estudos sobre o materialismo histórico-dialético e a teoria histórico-cultural e, ainda, com o desenvolvimento de investigações pelos pesquisadores do grupo, o conceito de $\mathrm{AOE}$ foi ampliado e seus princípios essenciais foram sistematizados para a organização do ensino e para a pesquisa sobre a atividade pedagógica.

No âmbito das diversas pesquisas ancoradas no conceito de Atividade Orientadora de Ensino, desenvolvidas por pesquisadores que trabalham com essa perspectiva teórica para a organização do ensino, duas vertentes vêm se configurando: a utilização do conceito para a organização da atividade pedagógica e como instrumento metodológico de pesquisas sobre o ensino [...]. (Moura et al.; 2010, p. 220)

Quando se trata da AOE no processo de pesquisa educacional, vários membros do GEPAPe têm se debruçado para o entendimento desse processo, dentre os trabalhos destacam-se: Araújo (2012); Cedro e Moura (2012), Panossian e outros (2017); Araújo e Moraes (2017). O presente artigo tem o intuito de dar continuidade a esse trabalho e compreender o lugar da AOE no movimento investigativo sobre a atividade pedagógica. A questão central que procuramos responder é a seguinte: "Como as pesquisas desenvolvidas no GEPAPe tem se apropriado do conceito de AOE para desvelar o fenômeno investigado?

Deste modo, destacamos que a ampliação da compreensão da AOE como modo geral para organização do ensino e como instrumento teórico-metodológico para a investigação sobre a atividade pedagógica é decorrente do próprio movimento do conceito e das necessidades dos pesquisadores que têm esse referencial para

1 O GEPAPe é um grupo de pesquisa cadastrado no CNPq e coordenado pelo Prof. Dr. Manoel Oriosvaldo de Moura, sediado na Faculdade de Educação da USP. 
a realização da pesquisa educacional. O lugar social ao qual muitos membros pertencem, isto é, como professores orientadores de pesquisas, suscitou, também, a necessidade de se pensar a AOE articulada com a investigação sobre a atividade pedagógica. Importante ressaltar que os membros do GEPAPe, em sua maioria, atuam em diferentes programas de pós-graduação do país.

Outro ponto a destacar é o entendimento sobre o compromisso político e social dos participantes do GEPAPe ao desenvolverem o ensino e a pesquisa tendo como referencial a teoria histórico-cultural e a AOE, o qual traz incorporado a defesa da educação escolar como condição para emancipação humana dos sujeitos.

Para atingir o objetivo proposto para este texto, realizamos uma pesquisa de cunho documental baseada em dezenove teses produzidas no GEPAPe no período de 2003 a 2016. Desse modo, consideramos trabalhos científicos que investigam um problema de pesquisa e que, em razão da própria condição de sua produção, revelam mais aprofundamento sobre o fenômeno investigado. Dessa forma, os trabalhos escolhidos evidenciam-se como amostra significativa sobre o modo de desenvolver pesquisas em educação sobre a atividade pedagógica no GEPAPe.

Verifica-se que o texto está organizado em três tópicos. No primeiro, abordamos a AOE como fundamento teórico- metodológico para a produção e análise dos dados da pesquisa no âmbito do GEPAPe. No segundo, tratamos de expor como as investigações empregam o conceito AOE para a organização do ensino, isto é, o desdobramento do conceito de AOE. No terceiro, abordamos a pesquisa como atividade, destacando seus elementos essenciais e a constituição do pesquisador no processo investigativo.

\section{A AOE e o processo de produção e análise de dados}

Nesta seção, faremos uma descrição sucinta da relação existente entre a AOE e o processo de produção de dados e análise nas pesquisas desenvolvidas no âmbito do GEPAPe. Em Panossian e outros (2017), há uma discussão profunda deste aspecto da AOE, feita com base em uma determinada amostra da produção do grupo que englobava teses e dissertações que tinham como foco a formação do professor que ensina matemática.

Como neste texto o corpus refere-se somente às teses, utilizaremos as categorias propostas em Panossian e outros (2017) para identificar se a AOE aparece como elemento da metodologia de pesquisa ou como elemento de análise. Assim, no quadro a seguir, a coluna "produção dos dados" identifica se o trabalho fez uso dos princípios da AOE para organização do espaço formativo em que seriam produzidos os dados. Na coluna "análise dos dados" observou-se como os trabalhos utilizaram a AOE na análise dos dados, isto é, se o conceito esteve presente na construção das categorias ou 
unidades de análise, ou seja, se os elementos da AOE apareceram durante o processo analítico.

Quadro 1: A AOE nas teses do GEPAPe

\begin{tabular}{|c|c|c|c|c|}
\hline $\mathbf{N}$ & AUTOR & ANO & AOE & \\
\hline 1 & Algacir J R & & \multirow{4}{*}{$\begin{array}{l}\text { Espaço formativo } \\
\text { previamente } \\
\text { organizado }\end{array}$} & Análise de dados \\
\hline 2 & ula Gladcheff & & & Categorias de \\
\hline & & & & $\begin{array}{l}\text { análise criadas com } \\
\text { base nos elementos } \\
\text { da AOF }\end{array}$ \\
\hline 3 & Anemari R. L. V. Lopes & 2004 & & $\begin{array}{l}\text { Elementos da AOE } \\
\text { surgem no processo } \\
\text { analítico }\end{array}$ \\
\hline 4 & Carolina P. Nascimento & 2014 & & \\
\hline 5 & Elai & 2003 & $\begin{array}{l}\text { Espaço formativo } \\
\text { organizado pelo } \\
\text { pesquisador }\end{array}$ & $\begin{array}{l}\text { Elementos da AOE } \\
\text { surgem no processo } \\
\text { analítico }\end{array}$ \\
\hline 6 & da S.F.Asbahr & 2011 & \multirow{3}{*}{$\begin{array}{l}\text { Espaço formativo } \\
\text { previamente } \\
\text { organizado }\end{array}$} & \\
\hline 7 & Fláv & 2011 & & $\begin{array}{l}\text { Elementos da } \mathrm{AOE} \\
\text { surgem no processo } \\
\text { analítico }\end{array}$ \\
\hline 8 & Furlanett & 2013 & & \\
\hline & M.Be & 2006 & $x x$ & Elementos da AOE \\
\hline 11 & Maria Lucia Panossian & 2014 & \multirow{3}{*}{$\begin{array}{l}\text { Espaço formativo } \\
\text { organizado pelo } \\
\text { pesquisador }\end{array}$} & surgem no processo \\
\hline 12 & Marisa da S. Dias & 2007 & & $\begin{array}{l}\text { anallico } \\
\text { Categorias de } \\
\text { análise criadas com } \\
\text { base nos elementos } \\
\text { da AOE }\end{array}$ \\
\hline \multirow{2}{*}{$\begin{array}{l}13 \\
14\end{array}$} & la R. Mi & 2010 & & \multirow{2}{*}{$\begin{array}{l}\text { Elementos da AOE } \\
\text { surgem no processo } \\
\text { analítico. }\end{array}$} \\
\hline & eF.Sfo & 2003 & $x \mathrm{x}$ & \\
\hline 15 & Neuton A. de A. Calaça & 2016 & \multirow[t]{2}{*}{$\begin{array}{l}\text { Espaço formativo } \\
\text { previamente } \\
\text { organizado }\end{array}$} & $\begin{array}{l}\text { Categorias de } \\
\text { análise criadas com } \\
\text { base nos elementos } \\
\text { da AOE }\end{array}$ \\
\hline 16 & Ronaldo C. da Costa & 2016 & & \multirow{3}{*}{$\begin{array}{l}\text { Elementos da AOE } \\
\text { surgem no processo } \\
\text { analítico }\end{array}$} \\
\hline $\begin{array}{l}17 \\
18\end{array}$ & $\begin{array}{l}\text { Sílvia P. G. de Moraes } \\
\text { Vanessa D. Moretti }\end{array}$ & $\begin{array}{l}2008 \\
2007\end{array}$ & $\begin{array}{l}\text { Espaço formativo } \\
\text { organizado pelo }\end{array}$ & \\
\hline 19 & Wellington L. Cedro & 2008 & $\begin{array}{l}\text { Espaço formativo } \\
\text { previamente } \\
\text { organizado }\end{array}$ & \\
\hline
\end{tabular}




\section{Desdobramentos da AOE para a organização do ensino}

Como apresentamos anteriormente, a AOE tem sua gênese na organização do ensino da Matemática, em especial na construção do signo numérico em situação de ensino (Moura, 1992). Ao amparar-se em uma concepção de aprendizagem que pressupõe a relação com o outro e a importância das mediações simbólicas, sua estrutura considera a intencionalidade do professor como aquela que busca na estrutura da $\mathrm{AOE}$ "a própria gênese do conceito: o problema desencadeador, a busca de ferramentas intelectuais para solucioná-lo, o surgimento das primeiras soluções e a busca de otimização destas soluções" (Moura, 1992, p. 68).

Nesse sentido, compreender o movimento de produção histórica do conceito de $\mathrm{AOE}$ é importante para que possamos compreender também sua ampliação conceitual e de campo de atuação. Pois, a partir de meados da década 1990, passam a ser produzidas no âmbito do GEPAPe dissertações e teses que tomam o conceito de AOE como orientador da organização do ensino - tanto no contexto da educação básica quanto no contexto das ações de formação inicial e continuada de professores que constituem os espaços de investigações das referidas pesquisas. Assim, esse movimento de apropriação e significação do conceito de AOE revela os seus desdobramentos para a organização do ensino e como, nesse processo de significação, vão se constituindo suas principais características tomando-se por base as proposições iniciais de Moura (1992, 1996).

Desse modo, de acordo com Moura (1996) a estrutura da AOE deve conter: a síntese histórica do conceito; o problema desencadeador do processo de apropriação do conceito; e a síntese da solução coletiva, mediada pelo educador. Tais elementos, destacados por Moura e outros (2010, p. 100), objetivam uma forma de compreender o ensino destinado a favorecer o processo de aprendizagem humana. Nesse direcionamento, a AOE é compreendida como um elemento de "mediação entre a atividade de ensino e a atividade de aprendizagem". Tais atividades, embora tenham sujeitos distintos, constituem uma unidade dialética na $A O E$, uma vez que seus motivos devem coincidir e a separação entre elas se dá apenas com fim didático. $A$ forma humana de compreender a aprendizagem que ancora a estrutura da AOE toma como pressuposto princípios da teoria histórico-cultural que assume o humano como um ser social

[...] resultado do entrelaçamento do aspecto individual, no sentido biológico, com o social, no sentido cultural. Ou seja, ao se apropriar da cultura e de tudo o que a espécie humana desenvolveu - e que está fixado nas formas de expressão cultural da sociedade - o homem se torna humano. (Rigon; Asbahr; Moretti, 2010, p. 15-16)

Assim sendo, toma papel central nesse processo de constituição do homem a atividade humana (Leontiev, 1983). Como decorrência, o conceito de atividade também é central 
no processo de aprendizagem, o que faz com que, ao propor uma forma de organização do ensino em coerência com tais pressupostos, a AOE considere os seus elementos estruturantes: necessidades, motivos, ações e operações. A organização do ensino, assim considerada, tende a possibilitar "a todos os indivíduos envolvidos no processo a apropriação dos nexos conceituais que permitam o amplo desenvolvimento da sua condição humana" (Cedro, 2008, p.59).

Em relação ao ensino, a AOE tem sido reconhecida como um modo geral para a organização do processo de ensino e de aprendizagem.

[...] reafirmamos que a Atividade Orientadora de Ensino é a mediação na atividade do professor que tem como necessidade o ensino de um conteúdo ao sujeito em atividade cujo objetivo é a apropriação desse conteúdo entendido como objetivo social. Nessa perspectiva, a AOE constitui-se em um modo geral de organização do ensino, em que seu conteúdo principal é o conhecimento teórico e seu objeto é a constituição do pensamento teórico do indivíduo no movimento de apropriação do conhecimento. (Moura et al, 2010, p. 221)

Nesse sentido, a compreensão da própria AOE como mediação entre a atividade de ensino e a atividade de aprendizagem é reforçada por Moura, Sforni e Lopes (2017, p. 71),

o ensino como atividade se realiza na Atividade Orientadora de Ensino [...] o que faz com que ela assuma características de mediação da formação do professor ao colocar em movimento, num mesmo processo, os conhecimentos teóricos (como síntese de modos de ação gerais gerados pela prática social) e as ações concretas da atividade de ensino do professor e da atividade de aprendizagem dos estudantes.

Assim, à estrutura inicial da AOE indicada por Moura (1996) aliam-se tanto a importância da intencionalidade do professor que, ao ter consciência e conhecimento sobre o objeto de ensino, cria condições para que esse se coloque como necessidade para aquele que aprende, quanto a garantia de um movimento mediado de produção coletiva para a solução do problema desencadeador.

Neste texto, tomando como campo para a análise as teses produzidas no âmbito do GEPAPe, verificamos, com base em Moura (1996) e Moura e outros (2010), dois elementos essenciais da AOE para a organização da atividade pedagógica, que são:

- situação desencadeadora de aprendizagem e a síntese histórica do conceito;

- atividade coletiva e mediação.

A seguir, apresentaremos como as teses analisadas tomaram tais elementos da $\mathrm{AOE}$ na organização do ensino. 


\section{Situação Desencadeadora de Aprendizagem e a Síntese Histórica do Conceito}

De acordo com Moura (1996), na AOE, a Situação Desencadeadora de Aprendizagem (SDA) tem por objetivo criar condições para que os sujeitos entrem em atividade de aprendizagem e, portanto, possam apropriarem-se de conceitos considerados socialmente relevantes (Moura; Sforni; Lopes, 2017). A SDA que busca mobilizar a atividade de aprendizagem pode ser objetivada por meio de diferentes recursos metodológicos. Dentre eles podemos destacar o jogo, as situações emergentes do cotidiano e a história virtual do conceito (Moura, 1996).

Sobre a natureza da SDA, Moraes (2008, p.99) com base em Rubtsov (1996), destaca que ela caracteriza-se como um problema de aprendizagem e não um problema prático:

Um problema concreto prático busca modos de ação em si, a aquisição de uma ação para a resolução de uma situação específica particular; já num problema de aprendizagem, o aluno se apropria de uma forma de ação geral, que se torna base de orientação das ações em diferentes situações que o cercam.

Entre as teses analisadas, diferentes pesquisadores (Cedro, 2008; Migueis, 2010; Moraes, 2008; Moretti, 2007, e outros), fundamentados em Moura (1996), ressaltam que a situação desencadeadora de aprendizagem se ancora na gênese histórica do conceito como forma de revelar a sua essência. Assim, a SDA "tem como essência a necessidade que levou a humanidade à construção do conceito" (Moretti, 2007, p 97).

Como consequência, temos que a SDA, composta por um problema de aprendizagem (Moraes, 2008), apoia-se na história do conceito como forma de reconhecer a necessidade humana que o motivou e, desta forma, colocar essa necessidade para os estudantes de modo a motivar o movimento da atividade de aprendizagem. Isso não significa reproduzir a história, o que se vincularia com a concepção piagetiana da recapitulação (Moretti; Radford, 2015), mas sim reconhecer a unidade entre seu aspecto lógico e o histórico. De acordo com Cedro (2008), a unidade entre o lógico e o histórico do conceito traz como implicação

[...] a necessidade de se perceber o movimento de gênese do conceito, não apenas como mais um elemento da História da Matemática, correndo o risco de esta converter-se em um próprio conteúdo matemático. Assim, a dimensão histórica do conhecimento matemático é entendida dentro do processo social e cultural do conceito. Nessa perspectiva, compreender a gênese do conceito significa perceber que ela faz parte da história, na qual os homens e as mulheres, perante as necessidades objetivas, buscaram e elaboram soluções para determinados problemas. (Cedro, 2008, p. 60) 
Na mesma direção, Moretti (2007) traz a discussão sobre os aspectos lógicos e históricos do conceito com base nas contribuições de Kopnin (1978), segundo o qual o lógico é "a reprodução da essência do objeto e da história do seu desenvolvimento no sistema de abstrações" (Kopnin, 1978, p. 183), é a apropriação do histórico pelo pensamento humano. Nessa compreensão, o conhecimento de um determinado conceito ou objeto de conhecimento implica na unidade dialética entre o aspecto lógico e o histórico o que traz implicações para a organização do ensino e, em particular, para o ensino da Matemática. Nesse sentido,

[...] é fundamental que a história do conceito permeie a organização das ações do professor de modo que esse possa propor aos seus alunos problemas desencadeadores que embutam em si a essência do conceito. Isso implica que a história da matemática que envolve o problema desencadeador não é a história factual, mas sim aquela que está impregnada no conceito ao se considerar que esse conceito objetiva uma necessidade humana colocada historicamente. (Moretti, 2007, p.99)

A proposição e elaboração de SDA no contexto da Atividade Orientadora de Ensino possibilita dar vida e movimento à intencionalidade da atividade pedagógica ao colocar para os sujeitos a necessidade do conceito e criar condições para que esses, ao entrarem em atividade, possam se apropriar de conhecimentos teóricos para a formação do pensamento teórico (Cedro, 2008). No entanto, a SDA não permite por si só a apropriação do conhecimento. A apropriação só se torna possível na atividade coletiva mediada.

\section{Atividade coletiva e mediação}

Uma vez que a AOE se apoia na concepção de aprendizagem defendida pela teoria histórico-cultural, temos que, para além da proposição da SDA, a forma como essa é desenvolvida no contexto da atividade de ensino deve garantir o movimento entre o individual e o coletivo de modo que, "independentemente da estratégia pedagógica utilizada, a atividade em comum, coletiva, é essencial na organização da AOE" (Asbahr, 2011, p.80).

Para Moura e outros (2010), considerar a solução da SDA na coletividade significa que são criadas estratégias didáticas que exijam dos sujeitos o compartilhamento de ações ou tarefas na busca da solução ao desafio colocado. Segundo o autor,

Garantir que a atividade de estudo dos educandos se dê prioritariamente dentro de um coletivo, busca concretizar o princípio ou lei de formação das funções psíquicas superiores elaborado pela Teoria histórico-cultural em acordo com o que preconiza Vigotski. [...]. Neste sentido, o compartilhamento assume o significado da coordenação 
das ações individuais em determinada situação-problema comum aos indivíduos. (Moura et al., 2010, p.225)

De modo geral, a atividade coletiva na $\mathrm{AOE}$ tem sido intencionalmente organizada pelo educador partindo de uma situação inicial de trabalho em pequenos grupos cujas produções são socializadas no coletivo do espaço de ensino/formação com vistas à elaboração da "síntese coletiva, mediada pelo educador" (Moura, 1996).

Os pesquisadores que têm tomado a $\mathrm{AOE}$ como um referencial para a organização do ensino (Araújo, 2003; Lopes, 2004; Bernardes, 2006; Moretti, 2007; Cedro, 2008; Moraes, 2008; Gladcheff, 2015; Panossian, 2014, entre outros), em coerência com essa fundamentação, destacam a importância da atividade coletiva que se dá em um espaço mediado por signos, instrumentos e sujeitos. Sobre a importância da mediação, Bernardes (2006) destaca que considerando a fundamentação teórica histórico-cultural da $\mathrm{AOE}$, essa assume que "o conhecimento é produto das interrelações pessoais e é mediado por instrumentos simbólicos organizados a partir de necessidades coletivas e individuais" (Bernardes, 2006, pp.123-124).

Apoiada em Makarenko (2012), Gladcheff (2015) apresenta o conceito de coletividade como um "complexo de indivíduos que possuem um objetivo determinado" e destaca como em sua pesquisa a coletividade pôde "proporcionar aos professores, por meio das ações de cada um dos integrantes, a objetivação de uma necessidade que é comum a todos" (Gladcheff, 2015, p.59).

Também, referindo-se à coletividade na organização do ensino, Dias (2007, p. 110) destaca em sua pesquisa que "a coletividade é um pressuposto da atividade humana para qual a atividade orientadora de ensino se dirige, pois ao constituir a coletividade, o indivíduo se constitui" e que, na formação de professores, "é a partir das suas ações combinadas que surgem as possibilidades de mudança de qualidade do indivíduo e da própria coletividade" (Dias, 2007, p. 110).

De forma geral, como destaca Cedro (2008), o papel do professor na coletividade em movimento na AOE, é

[...] criar condições para que os indivíduos interajam motivados pela tentativa de dar resposta a determinado problema, de forma que ocorra um fluxo ininterrupto no processo de elaboração compartilhada da solução que abarque tanto os indivíduos isolados, quanto os pequenos grupos e o coletivo da sala de aula. (Cedro, 2008, p. 60)

Temos, assim, que viabilizar, na AOE, um espaço de solução coletiva para a apropriação do conhecimento teórico só é possível por meio da intencionalidade do professor que compreende o coletivo como espaço de produção e apropriação da cultura humana historicamente produzida.

Isso posto, compreendidas as contribuições e desdobramentos da AOE para a 
organização do ensino, buscaremos no próximo item analisar seus desdobramentos para a pesquisa.

\section{A pesquisa como atividade}

Assumir a pesquisa como atividade, implica em adjetivá-la como formativa. A formação é entendida como um projeto que se preocupa com "seu potencial reconstrutor, alicerçada no compromisso ético, político e sociocultural" (Araújo; Moura, 2008, p. 98).

Nessa perspectiva, da pesquisa como atividade, o pesquisador tem a possibilidade de uma formação profissional e acadêmica, portanto, pressupõe um processo que envolve tanto a formação acadêmica como pesquisador quanto o desenvolvimento profissional da docência. Assim, compreendemos que a pesquisa como atividade envolve colaboração, reflexão, ação, (trans)formação e mediação.

Ao se compreender a pesquisa como atividade, como se defende neste trabalho, é necessário destacarmos algumas características (Araújo; Moraes, 2017):

- contém a síntese de um projeto coletivo;

- tem uma necessidade coletiva;

- tem um plano de ação coordenado;

- coincide motivo com objeto;

- ser sujeito da pesquisa.

A seguir, ilustraremos, com trechos extraídos das teses produzidas no âmbito do GEPAPe, as características que nos ajudam a compreender a pesquisa como atividade.

Nas análises das teses, encontramos indicadores de transformações do pesquisador, no decorrer do trabalho investigativo, que mostram como a pesquisa passa a ser concebida como uma atividade para o sujeito e, portanto, carrega consigo o potencial transformador. 


\section{Conter a síntese de um projeto coletivo}

A inserção nas atividades do GEPAPe possibilitou aos sujeitos as condições necessárias para que a atividade de pesquisa passasse a ser significativa. Isso ocorre porque a perspectiva de pesquisa do GEPAPe surge em decorrência das relações históricas do próprio grupo, considerando o histórico da produção científica dos pesquisadores vinculados a ele, assim como das leituras e seminários organizados para o aprofundamento teórico-metodológico sobre os pressupostos do materialismo histórico dialético e da teoria histórico-cultural. Como fundamento teórico-metodológico, a atividade é a categoria de análise do materialismo histórico dialético para a compreensão do desenvolvimento humano.

É dentro desse movimento de compreensão da atividade pedagógica, promovido pelo GEPAPe, que os sujeitos se defrontam com um projeto coletivo de formação. No trecho de Rigon (2011, p. 190), fica evidente que a pesquisa contém a síntese de um projeto coletivo.

No grupo de pesquisa, a discussão coletiva, aos poucos, foi gerando novas ideias, novas visões de mundo. A contribuição do grupo, de modo especial do orientador, foi decisiva para formar a "ideia do coletivo". Não somente no aspecto teórico, de que o grupo é imprescindível na formação do indivíduo, bem como de que a única forma de sobreviver, encontrar saídas numa sociedade classista é a vida em grupo. Mas, principalmente, no fato de ele ter me inserido numa atividade tal que esta ideia, visão de mundo, emerge como característica do sujeito sem ter ficado, insistentemente, falando da mesma.

Essa mesma compreensão é reforçada no trecho extraído da tese de Bernardes (2006, p. 148), como podemos ver a seguir:

O processo de formação como professora-pesquisadora não ocorre de forma isolada, mas junto a grupos de estudo que possibilitam o compartilhar de conhecimentos que criam situações para que ocorra a transformação das condições iniciais postas pela formação anterior.

Nos dois excertos anteriormente apresentados, fica latente, no discurso dos sujeitos, que eles cairiam em contradição caso afirmassem que os trabalhos produzidos eram uma produção individual, muito pelo contrário, eles reafirmam que as teses produzidas decorrem da produção coletiva do grupo. 


\section{Ter uma necessidade coletiva}

Sabemos que os processos formativos na sociedade burguesa se reduzem a individualizar a personalidade, para que cada pessoa se adapte à luta pela existência pessoal (Makarenko, 1977). Nesse sentido, é importantíssimo que as necessidades não estejam simplesmente atreladas aos desejos e anseios do indivíduo isolado, mas que surjam do trabalho coletivo. No trecho a seguir, fica evidente esse movimento.

Por fim, ressaltar que foi esse o processo de formação do pesquisador [...], minha trajetória, na qual os momentos foram diversos, oscilando entre momentos em que fui engolfado pelo "espírito individualista", e momentos em que se recobra a consciência e a importância do coletivo. (Rigon, 2011, p.201)

O trecho acima demonstra a importância do coletivo nos processos formativos do pesquisador e do sujeito. Conforme Petrovski (1984, p.62):

Assim como o indivíduo modifica em sua atividade objetivada o mundo circundante e deste modo modifica a si mesmo convertendo-se em personalidade, o grupo social, em sua atividade conjunta socialmente significativa, constrói ou modifica o sistema das relações interpessoais e da interação pessoal convertendo-se em coletividade.

Essa atividade coletiva é mais uma vez enfatizada no trecho a seguir:

Ao finalizarmos este texto, descrevemos uma síntese do processo de nossa formação como pesquisadora e profissional da educação. Entendemos ser este um processo individual, mas que possui raízes sócio-históricas e, portanto, possui no coletivo o referencial para seu desenvolvimento. Desta forma, continuaremos a escrita na primeira pessoa do plural por termos como referência de formação a coletividade proporcionada pelos vários grupos que integramos durante o percurso da pesquisa. (Gladcheff, 2015, p.249)

Fica evidente no discurso de Gladcheff (2015) "que fora da coletividade não é possível formar uma personalidade com alto grau de consciência, sentido de responsabilidade ante a sociedade e elevadas qualidades morais", conforme afirma Makarenko (1977, p.5). 


\section{Ter um plano de ação coordenado}

O que é pesquisa? Por que se deve fazer uma pesquisa? Para que serve? Como devo fazer?

O leitor pode se questionar por que fazermos perguntas singelas como essas, mas que possuem respostas que flertam com o senso comum ou que estão totalmente imersas em complexas explicações teóricas. A escolha por esses questionamentos recai na necessidade de não perdermos o sentido da atividade de pesquisa.

Conceber a pesquisa como uma atividade implica um entendimento de que ela constitui um instrumento que pode ser tanto físico ou simbólico, externo ou interno (Leontiev, 1983) e que, portanto, determina os métodos e as operações. O entendimento semântico que se tem de uma pesquisa, como o procurar com cuidado, o procurar por toda a parte, o inquirir, o informar-se bem, adquire uma nova qualidade. A pesquisa passa a ser entendida como uma atividade humana (Leontiev, 1978; 1983) e, sendo assim, é eminentemente criadora, social e coletiva.

Desse modo, ao admitirmos e concebermos a pesquisa como atividade, defendemos a unidade entre forma e conteúdo, o que significa considerar que o método, é a própria alma do conteúdo, ou seja, esses conhecimentos se materializam na forma do método e das metodologias.

Nessa perspectiva, a pesquisa como atividade tem como um dos seus princípios o rigor conceitual. O rigor aqui é entendido no sentido de que se objetiva produzir conhecimento, e não dar opinião, sobre determinado contexto e para isso há que atentar para a relação conteúdo e forma.

No trecho a seguir, Gladcheff (2015, p. 250) deixa bem claro essas ideias:

Percebíamos, a todo o momento, a complexidade da pesquisa, o que a tornava cada vez mais desafiadora. O envolvimento com o projeto "Observatório da Educação" não era só como pesquisadora, mas como sujeito que também estava se transformando. Ao mesmo tempo em que aprendíamos como profissionais da educação com os professores e com todo o processo, não podíamos nos descuidar de nossa atividade principal: a pesquisa.

Não se descuidar com a pesquisa implica em compreender um modo de ação, isto é, em estabelecer um plano de ação coordenado. Na pesquisa como atividade, que se fundamenta na teoria histórico-cultural, o pressuposto básico é que existe a necessidade de rigor conceitual da investigação no sentido de que se objetiva na produção de conhecimento e não descrição sobre determinado fenômeno.

Nesse sentido, a tentativa de compreender, explicar a realidade realiza-se por meio de um movimento de intervenção nessa mesma realidade (Freitas, 2010). No trecho a seguir percebemos com clareza esse movimento. 
Um [...] aspecto no movimento de aprendizagem da pesquisadora em que se discute o processo de conhecimento do fenômeno e de constituição de um modo de fazer pesquisa está em evidenciar a relação dialética estabelecida com o referencial do método histórico-dialético, a atividade prática no campo de pesquisa e a atividade teórica de conhecimento do fenômeno, presente nas manifestações dos estudantes e reveladoras de um processo de apropriação de elementos do modo geral de organização do ensino a atividade prática no campo de pesquisa e a atividade teórica de conhecimento do fenômeno, presente nas manifestações dos estudantes e reveladoras de um processo de apropriação de elementos do modo geral de organização do ensino. (Ribeiro, 2011, p.165)

Temos ,nessa forma de pesquisar, o movimento do pesquisador e dos sujeitos da pesquisa, visto que o eixo norteador é a categoria atividade.

\section{Coincidir motivo com objeto}

Lembremos que a atividade constitui-se nos "processos que são psicologicamente determinados pelo fato de aquilo para que tendem no seu conjunto (o seu objeto) coincidir sempre com o elemento objetivo que incita o indivíduo a uma dada atividade, isto é, com o motivo" (Leontiev, 1978, p.315).

Daí, decorre que para a pesquisa ser compreendida como atividade, há necessidade do motivo e objeto coincidirem. No trecho extraído de Moraes (2008, p. 244), percebemos com clareza essa coincidência entre os elementos da atividade.

A realização desta investigação, em parceria com os professores da rede pública de ensino, oportunizou à pesquisadora um exercício singular sobre o processo de elaboração de novos conhecimentos e, também, de aprendizagem docente como professora do ensino superior.

Em Lopes (2004, p. 173), temos outro trecho que reforça esse movimento de coincidência do motivo e do objeto, e mais, que o motivo inicial vai se transformando.

Como formadores de professores, fomos levados a desenvolver esse trabalho pela necessidade de conhecer mais profundamente o processo de aprendizagem docente de futuros professores. Agora, o seu término nos motiva a desenvolver uma nova atividade, que continua sendo a de formadores de professores. Contudo, a partir do desenvolvimento de novas ações e outras qualidades proporcionadas por essa pesquisa.

Percebe-se que os motivos foram se transformando e alguns novos surgiram à medida que as ações se estabeleceram significativamente para o indivíduo. Nesse processo, as novas ações propostas tinham como objetivo um novo motivo e, dessa forma, há a 
coincidência entre esse e o produto objetivado. Assim, a pesquisa, ao coincidir motivo e objeto, passa a constituir-se como atividade para o pesquisador.

\section{Ser Sujeito da Pesquisa}

Rigon (2011, p. 191) deixa claro, no extrato reproduzido a seguir, o aspecto formativo da pesquisa para o sujeito:

Em meu caso particular, foi na experiência de vida individualizada que tomo consciência, definitiva, de quanto a atividade coletiva é propulsora e constituinte dos indivíduos no sentido de fazerem destes verdadeiros sujeitos.

Essa mesma dimensão formativa, também é encontrada nas reflexões de Panossian (2014, p. 269):

Nesses movimentos de análise e síntese em busca de investigar a relação entre o movimento histórico e lógico dos conceitos e o objeto de ensino da álgebra, a pesquisadora se apresenta como sujeito da pesquisa, que aos poucos vai se constituindo.

Ao analisarmos o discurso do pesquisador, percebemos que as ações formativas durante o desenvolvimento da investigação foram imprescindíveis para a mudança qualitativa na atividade profissional do sujeito (Araújo; Moura, 2008). Esta transformação somente poderá ser concretizada quando o indivíduo apropriar-se dos conhecimentos culturais, científicos, teóricos e técnicos, que são instrumentos necessários para ir além das aparências e que permitem a decodificação e interpretação do mundo real. A consequência disso é o estabelecimento de relações mais conscientes com os acontecimentos sociais e históricos.

Reforçando esse aspecto da pesquisa como atividade, o discurso de Asbahr (2011, p. 191), no trecho que se segue, explicita a transformação qualitativa das ações:

Este percurso não foi fácil, pois exigiu não apenas transformações e rearranjos nas minhas concepções teóricas e nas minhas formas de pensar, mas principalmente modificou-me como pessoa. Avalio que a concepção teórica eleita por mim não se refere apenas ao trabalho acadêmico, como se fosse uma ferramenta conceitual de análise, mas é fundamentalmente um posicionamento ético-político frente à realidade, que modifica meus pensamentos e minhas ações e exige coerência teórico-prática. É essa coerência que tenho buscado em minhas ações acadêmicas, profissionais e pessoais. Esta tese coroa, de certa forma, essa busca.

Analisando as palavras de Asbahr (2011) e dos demais pesquisadores analisados nesse texto, podemos vislumbrar uma perspectiva importante para a formação do 
pesquisador e, por consequência, do sujeito que permita a ele a inserção no movimento de busca do sentido pelo que faz. Uma perspectiva que lhe possibilitará compreender os limites que configuram as práticas sociais inerentes à pesquisa, que não é seduzida pelos modismos teóricos, que nos afastará da visão utilitarista e das respostas fáceis à necessidade de mudança na formação do pesquisador.

Na direção acima, concordamos com Moura (2004, p. 259) quando discute o movimento de busca pelo sentido da atividade.

A nossa busca de sentido pela vida talvez seja o que mais nos aflige e talvez o que mais pode nos mobilizar na perspectiva de nos constituir, como coletivo, para a satisfação do que pode ser a nossa necessidade básica de hoje: o sentido de continuarmos buscando um rumo para a humanidade.

Assim, é somente na coletividade que podemos compreender a transformação dos sujeitos e a superação dos processos de alienação da atividade impostos pela sociedade contemporânea regida pelo sistema capitalista de produção.

\section{Considerações finais}

A análise das teses desenvolvidas pelo GEPAPe revelou o movimento de produção do conceito de $\mathrm{AOE}$, desde a organização do espaço formativo para produção e análise dos dados até suas características essenciais para pesquisa como atividade, evidenciando assim, um modo singular de realizar pesquisa em educação tendo como objeto a atividade pedagógica.

A organização do espaço formativo para produção dos dados permitiu ampliar e sistematizar o conceito de AOE tanto para o ensino como para a pesquisa em educação. Essas investigações, tomadas em seu conjunto, permitiram sistematizar as principais características da pesquisa como atividade, a saber: conter a síntese de um projeto coletivo; a necessidade coletiva; um plano de ação coordenado; coincidir o motivo com objeto e o sujeito estar em atividade.

A dimensão formativa para o ensino e a pesquisa se insere no movimento de formarformando ou investigar-formando-se. Pois, a constituição dos sujeitos em atividade é central nesse processo: pesquisador em atividade; participantes da pesquisa, também, em atividade. Neste movimento que é possível coincidir o motivo com o objeto da atividade. Conforme palavras de Moura e outros (2010, p. 221)

[...] a AOE constitui-se em um modo geral de organização do ensino, em que seu conteúdo principal é o conhecimento teórico e seu objeto é a constituição do pensamento teórico do indivíduo no movimento de apropriação do conhecimento. Assim, o professor, ao 
organizar as ações que objetivam o ensinar, também requalifica seus conhecimentos, e é esse processo que caracteriza a AOE como unidade de formação do professor e do estudante.

Essa citação evidencia a AOE como modo geral de organização do ensino e permite "que cada indivíduo aproprie da 'força social' produzida pelo homem e objetivada nos signos, particularmente nos conceitos teóricos" (Cedro e Nascimento, 2017, p. 41).

$\mathrm{Na}$ análise das teses, constatamos dois focos de pesquisas mais recorrentes: a formação de professores e a organização do ensino, em especial de matemática. "Na dimensão da formação do professor, Moura (2001) afirma que a atividade orientadora resgata o sentido da 'profissão-professor'" (Bernardes, 2006, p.124). Em relação ao ensino de Matemática Moretti (2007, p. 101) destaca que:

[...] a atividade orientadora de ensino, ao propor a organização do ensino a partir de situações-problema fundamentadas na necessidade da história do conceito e em ações docentes coletivamente a sua solução, pode ser desencadeadora da transformação da prática docente, com vistas a uma educação que entendemos como humanizadora dos sujeitos envolvidos no processo de ensino e de aprendizagem.

O grande desafio é o desenvolvimento de pesquisas e a organização do ensino tendo como referência a AOE, fundamentadas no materialismo histórico-dialético e na teoria histórico-cultural no contexto de uma sociedade capitalista, visto que as condições, tanto para o pesquisador no processo investigativo, como para os professores e demais trabalhadores da educação na organização da atividade pedagógica, caminham na direção contrária do processo de emancipação humana dos sujeitos. Entretanto, ao mesmo tempo que temos limites para a prática educativa, temos, também, as possibilidades para a mudança. De acordo com Gramsci (1995, p. 47):

A possibilidade não é a realidade, mas é, também ela uma realidade: que o homem possa ou não fazer determinada coisa, isto tem importância na valorização daquilo que realmente faz. Possibilidade quer dizer "liberdade". A medida da liberdade entra na definição de homem. Que existam as possibilidades objetivas de não se morrer de fome e que, mesmo assim se morra de fome, é algo importante, ao que me parece. Mas a existência de condições objetivas - ou possibilidade, ou liberdade - ainda não é suficiente: é necessário "conhecê-las" e saber utilizá-las. Querer utilizá-las.

Destacamos que a coletividade construída no GEPAPe revela esse movimento de possibilidade e de liberdade no processo histórico-social de produção científica sobre a pesquisa em educação como atividade e sobre a organização da atividade pedagógica - destinada à emancipação humana dos sujeitos envolvidos no processo educativo. 


\section{Referências}

Araújo, E. S. (2012). Contribuições da teoria histórico-cultural à pesquisa em educação matemática: a Atividade Orientadora de Pesquisa. In: Reunião Anual da Anped, 35., 2012, Porto de Galinhas, PE. Anais..., Porto de Galinhas-PE: Associação Nacional de Pós-Graduação e Pesquisa em Educação Matemática.

Araújo, E. S. (2003). Da formação e do formar-se: a atividade de aprendizagem docente em uma escola pública. Tese (Doutorado em Educação) - Faculdade de Educação, Universidade de São Paulo.

Araújo, E. S.; Moraes, S. P. G. (2017). Dos princípios da pesquisa em educação como atividade. In M. O. de MOURA. Educação escolar e pesquisa na teoria na históricocultural. São Paulo: Loyola, p.47-70.

Araújo, E. S.; Moura, M. O. (2008). Contribuições da teoria histórico-cultural à pesquisa qualitativa sobre formação docente. In S. G. Pimenta; M. A. S. Franco (orgs.). Pesquisa em educação: possibilidades investigativas/formativas da pesquisaação. vol.1. São Paulo: edições Loyola, p.75-102.

Asbahr, F. S. F. (2011). Por que aprender isso, professora? Sentido pessoal e atividade de estudo na Psicologia histórico-cultural. 219 p. Tese (Doutorado) - Instituto de Psicologia - Universidade de São Paulo.

Bernardes, M. E. M. (2006). Mediações simbólicas na atividade pedagógica: contribuições do enfoque histórico-cultural para o ensino e aprendizagem.330p. Tese (doutorado) - Faculdade de Educação - Universidade de São Paulo.

Cedro, W. L. (2008). O motivo e a atividade de aprendizagem do professor de Matemática: uma perspectiva histórico-cultural. 2008. 242 p. Tese (Doutorado) Faculdade de Educação, Universidade de São Paulo.

Cedro, W. L.; Moura, M. O. (2012). Investigação sobre a atividade pedagógica: os caminhos percorridos no GEPAPe. Educação em Foco (Juiz de Fora), v. 1, p. 61-73.

Cedro, W. L.; Nascimento, C. P. (2017). Dos métodos e das metodologias em pesquisas educacionais na teoria histórico-cultural. In: M. O. de MOURA (Org.). Educação escolar e pesquisa na teoria histórico-cultural. São Paulo: Edições Loyola. p. 13-46.

Dias, M. S. (2007). Formação da imagem conceitual da reta real: um estudo do desenvolvimento do conceito na perspectiva lógico-histórica. 2007. 252 p. Tese (Doutorado) - Faculdade de Educação, Universidade de São Paulo. 
Freitas, M. T. de A. (2010). Discutindo sentidos da palavra intervenção na pesquisa histórico-cultural. In M. T. de A. Freitas; B. S. Ramos (orgs). Fazer pesquisa na abordagem histórico-cultural: metodologias em construção. Juiz de Fora, MG: Ed. UFJF, p.13-24.

Gladcheff A. P. (2015). Ações de estudo em atividade de formação de professores que ensinam matemática nos anos iniciais. 2015. 287 p. Tese (Doutorado) - Faculdade de Educação, Universidade de São Paulo.

Gramsci, A. (1995). Concepção dialética da História. Tradução de Carlos Nelson Coutinho. 10. ed. Rio de Janeiro: Ed. Civilização Brasileira, 341 p.

Kopnin, P. V. (1978). A dialética como lógica e teoria do conhecimento. Rio de Janeiro: Civilização Brasiliense.

Leontiev, A. (1983). Actividad, conciencia, personalidad. Havana: Editorial Pueblo y Educación.

Leontiev, A. (1978). O desenvolvimento do psiquismo. Lisboa: horizonte universitário. Lopes, A. R. L. V. (2004). Aprendizagem docente no estágio compartilhado. Tese (Doutorado) - Faculdade de Educação, Universidade de São Paulo.

Makarenko, A. (2012). Poema Pedagógico. São Paulo: Editora 34.

Makarenko, A. (1977). La colectividad y la construcción de la personalidad. Moscú: editorial progreso.

Migueis, M. da R. (2010). A formação como atividade de aprendizagem docente. 263 p. Tese (Doutorado) - Departamento de Ciências da Educação, Universidade de Aveiro, Portugal.

Moretti, V. D. (2007). Professores de matemática em atividade de ensino: uma perspectiva histórico-cultural para a formação docente. 207 p. Tese (Doutorado) - Faculdade de Educação, Universidade de São Paulo.

Moretti, V. D.; Radford. L (2015). História do conceito culturalmente significada e a Organização da Atividade de Ensino de Matemática. In: VI Sipem - Simpósio Internacional de Pesquisa em Educação Matemática, 2015, Pirenópolis. Anais do VI Sipem.

Moraes, S. P. G. (2008). A avaliação do processo de ensino e de aprendizagem em Matemática: contribuições da teoria histórico-cultural. 260 p. Tese (Doutorado em Educação) Faculdade de Educação, Universidade de São Paulo.

Moura, M. O. de (2004). Pesquisa colaborativa: um foco na ação formadora. In: R. 
L. Leite B. (org.). Trajetórias e perspectivas da formação de educadores. São Paulo: editora da UNESP, p. 257-284.

Moura, M O. de. (2001). A atividade de ensino como ação formadora. In: A. D. Castro; A. M. P. CARVALHO (Orgs.). Ensinar a ensinar: São Paulo: Pioneira.

Moura, M. O. de (1996). A atividade de ensino como unidade formadora. Bolema, Ano II, n. 12. p. 29-43.

Moura, M. O. de (1992). A construção do signo numérico em situação de ensino. 1992, 151 f. Tese (Doutorado em Educação: Ensino de Ciências e Matemática) Universidade de São Paulo, São Paulo.

Moura, M. O. de; Araújo, E. S.; Moretti, V. D.; Panossian, M. L.; Ribeiro, F. D. (2010). Atividade orientadora de ensino: unidade entre ensino e aprendizagem. Revista Diálogo Educacional, v. 10, n. 29, p. 205-229.

Moura, M. O. de; Sforni, M. S. F.; Lopes, A. R. L. V. (2017) Objetivação do Ensino e o desenvolvimento do Modo Geral de Aprendizagem da Atividade Pedagógica. In: M. O. de Moura (Org.). Educação escolar e pesquisa na teoria histórico-cultural. São Paulo: Edições Loyola. p. 71-100.

Panossian, M. L. (2014). O movimento histórico e lógico dos conceitos algébricos como princípio para constituição do objeto de ensino da álgebra. 317 p. Tese (Doutorado) - Faculdade de Educação, Universidade de São Paulo, São Paulo. Panossian, M. L.; Marco, F. F. de; Lopes, A. R. L. V.; Souza, F. D.; Moretti, V. D. (2017). $A$ atividade orientadora de ensino como pressuposto teórico-metodológico de pesquisas. Revista Reflexão e Ação, Santa Cruz do Sul, v. 25, n. 3, p. 279-298, set./ dez.

Petrovski, A. (1984). Personalidad, actividad y colectividad. Buenos aires, argentina: Cartago.

Ribeiro, F. D. (2011). A aprendizagem da docência na prática de ensino e no estágio: contribuições da teoria da atividade. 196 p. Tese (Doutorado) - Faculdade de Educação, Universidade de São Paulo, São Paulo.

Rigon, A. J. (2011). Ser sujeito na atividade de ensino e aprendizagem. Tese (Doutorado) - Faculdade de Educação, Universidade de São Paulo, São Paulo.

Rigon, A. J.; Asbahr, F. S. F.; Moretti, V. D. (2010.) Sobre o processo de humanização. In: M. O. de Moura (Org.). A atividade pedagógica na teoria histórico-cultural. Brasília: Liber Livro, p. 13-44. 